\title{
How the COVID-19 Pandemic Impacts Lives of Life Scientists
}

\author{
Rüdiger E. Scharf ${ }^{1}$ \\ 1 Program in Cellular and Molecular Medicine, Boston Children's \\ Hospital, Harvard Medical School, Boston, Massachusetts, USA
}

Hämostaseologie 2021;41:9-13.

The coronavirus has caused a pervading disaster worldwide. In fact, the COVID-19 pandemic is not a crisis but a catastrophe, facing the dramatic global increase in morbidity and mortality rates, and the SARS-CoV-2 outbreak has disrupted virtually everyone's daily life.

While the pandemic is having massive economic and environmental impacts, COVID-19 has also posed an unprecedented challenge to the scientific community. Thus, basic research and clinical investigations are being performed "at full speed" to explore the biology and evolution of SARS-CoV2 , evaluate the pathogenesis and epidemiology of the disease, elucidate host responses and host genetics, mitigate or prevent complications, and develop and test potential therapies. Until April 2020, more than 1,000 clinical studies worldwide pertaining COVID-19 were recorded. ${ }^{1}$ As a result of national and international activities and joint ventures, several anti-COVID-19 vaccines have been developed that have been or are being approved by the respective regulatory authorities and now available for mass-scale immunization of the population.

Apart from these activities and achievements, throughout the pandemic, many individual scientists have experienced a pressure to understand, mitigate, and cure COVID-19 or, at least, to provide a personal contribution in their field of expertise. ${ }^{2}$ Interestingly, Korbel and Stegle reported in a survey assessing the effects of the COVID-19 pandemic on life scientists that approximately $20 \%$ of the respondents indicated that they shifted their research focus with the aim to combat COVID-19. ${ }^{3}$

\section{Scientific Output, Up-To-Date Models of Publishing, and Shortcomings}

COVID-19 has caused a tremendous increase in the productivity and publication activities among investigators. Thus, until mid-December 2020, PubMed recorded more than 88,600 papers published in 2020 for the items "COVID-19," "SARS-CoV-2," and/or "coronavirus." ${ }^{4}$ For comparison only: in the same period of time, approximately 56,500 articles were published about cardiovascular disorders, causing 17.9 million deaths each year worldwide. ${ }^{4}$

The enormous number in coronavirus papers also reflects, at least in part, changes in the editorial and publication policy of the majority of scientific journals, now offering not only open access but also providing nontraditional publication tools such as registered reports, depositing submitted manuscripts (while still under peer review) on a preprint server, or adapting a larger report to a short communication format. ${ }^{5,6}$ Moreover, the editor-in-chief of eLife just announced to implement a "publish, then review" model of publishing, thereby making the posting of preprints a standard procedure. ${ }^{7}$

However, there are serious concerns about the rapid publication of COVID-19-related trials or intervention studies reporting insufficient, misleading, or biased results. Specifically, as demonstrated by an analysis of 1,694 registered COVID-19 studies, of which 698 (41\%) were randomized controlled trials (RCTs), only 35 RCTs (5\%) strictly adhered to established criteria of internal validity, such as blinding, allocation concealment, placebo (where applicable), and a data safety monitoring committee. ${ }^{8}$ In fact, accelerated publication of hot topics related to drug therapy (e.g., angiotensin-converting enzyme inhibitors; hydroxychloroquine or chloroquine $)^{9,10}$ of COVID-19, inaccuracies in data analysis due to incomplete dataset elements, other research or publication misconduct, and/or deviations from high-standard peer-review procedures resulted in the retraction of articles, even of those that had been published in top journals such as the New England Journal of Medicine and Lancet. $^{11-13}$
Address for correspondence Rüdiger E. Scharf, MD, PhD, FAHA, Visiting Professor of Pediatrics, Harvard Medical School, Program in Cellular and Molecular Medicine, Boston Children's Hospital, Karp Family Research Laboratories, 1 Blackfan Circle, RB09211.1, Boston, MA 02115, USA

(e-mail: ruediger.scharf@childrens.harvard.edu). (c) 2021. Thieme. All rights reserved. Georg Thieme Verlag KG, Rüdigerstraße 14 ,

70469 Stuttgart, Germany

Received

December 18, 2020

Accepted

December 19, 2020
DOI https://doi.org/

10.1055/a-1339-8671.

ISSN 0720-9355. 


\section{Impact of COVID-19 on Life Scientists}

Scientific output and publication modalities do not necessarily reflect the working conditions that scientists are facing with at times of COVID-19. Anecdotal accounts and personal experiences pertaining the implications and impact of the pandemic have been discussed extensively over the past few months on social media and popular press. By contrast, there are a few scientific reports only that have addressed the question of how COVID-19 has changed the research environment and how the pandemic has affected patterns in the daily work of life scientists. Specifically, only two studies have evaluated quantitative changes in the professional role or conditions and the workload among laboratory researchers. ${ }^{3,14}$

A recent survey conducted on scientists in Europe, Turkey, Canada, and the United States provided some insights into the extent of disruptions that scientists are experiencing, when research facilities have been partially or fully shut down. Among 881 individual responses (of which $72 \%$ from trainees, $17 \%$ from principal investigators and staff scientists, and $11 \%$ from support staff), approximately $50 \%$ of scientists indicated a reduction in research hours at the bench-with large differences between "wet lab" (73\%) and "dry lab" (31\%) investigators. ${ }^{3}$ Simultaneously, levels of self-perceived productivity dropped, whereby $29 \%$ of "dry lab" scientists but only $10 \%$ of "wet lab" scientists reported at least $80 \%$ productivity.

Not surprisingly, during times of lockdown, there was also a pronounced increase in self-perceived levels of stress among "wet lab" researchers, with higher increases among trainees and nontenured investigators. ${ }^{3}$ Other results (indicated as summary statistics) of this survey documented that the respondents spent "more time" on data analysis (43\%), manuscript (or thesis) writing (45\%), grant applications (11\%), paper reviewing (18\%), and networking with scientists at distance (10\%), while the rate of participants $(12 \%)$ who devoted "considerable time" to COVID-19-related crisis management was similar to the proportion of principal investigators and staff scientists (17\%) in this survey. ${ }^{3}$

Another survey analyzing more than 4,500 "full responses" from faculty or principal investigators in the United States and Europe reported on an overall decline in total working hours of $11 \%$, with an average dropping from 61 hours per week prepandemic to 54 hours in April 2020. ${ }^{14}$ However, not all scientists reduced the time devoted to research during the pandemic. Thus, $21 \%$ of the respondents reported spending more time on research and 9\% reported no change. ${ }^{14}$ Again, different fields or disciplines were affected differently. For example, bench scientists in biochemistry, molecular biology, genetic engineering, or chemistry reported largest declines in research time in the range of 30 to $40 \%$ below prepandemic levels. Conversely, fields that are less equipment-sensitive or do not rely on time-sensitive experiments exhibited the lowest decrease in research time. ${ }^{14}$

A very recent report, however, appears to be in conflict with the above findings. From May through June 2020, Rijs and Fenter conducted a large academic survey on more than 25,300 scientists worldwide. Among the 24,900 respondents (98\%), more than $70 \%$ of scientists felt that the massive disruption is "an inconvenience, but that they are capable of managing to perform the majority of their tasks", whereas approximately $20 \%$ indicated that their "professional role has changed completely" or that they are "no longer able to perform their work function", and approximately $10 \%$ stated that their "working processes are unaffected. ${ }^{15}$ Overall, the authors concluded that, despite the pandemic, researchers' day-to-day work has not been significantly affected by COVID-19 at the time of the survey, with many able to continue their professional role throughout. ${ }^{15}$ However, there was a large variation in the respondents' perception of disruption and shutdown depending on their country, local restrictions, and individual working conditions, all of which require further analysis. ${ }^{16,17}$

\section{Female Scientists with Young Children and Trainees from Abroad Are Disproportionally Affected}

The working conditions during the COVID-19 pandemic have also aggravated the gender disparity. This is evident from the few surveys available, reporting that female scientists (and specifically those with children younger than 5 years) have a 5 to $20 \%$ lager decline in research time than their male colleagues. This difference may reflect differences in childcare duties among both parents and suggests a particular vulnerability of female scientists during an institutional shutdown. ${ }^{3}$

Among life scientists, early-career researchers, such as junior faculty members, and immigrated trainees (PhD students, postdoctoral fellows), in particular those from a continent other than the one of their home countries, represent another specifically vulnerable group during the COVID-19 lockdown. ${ }^{17}$ As a direct consequence of uncertainty in planning, gaps in funding, local regulations and restrictions, such as winding down benchwork activities, downscaling experiments to a bare minimum, and cancelling university-related travel, psychological stress, anxiety, tension, or depression have increased among young scientists. This is vividly described in a recent report by Su, a research fellow from China working at Harvard Medical School, who also provided advice to overcome any despondency. ${ }^{18}$ Su's key messages are: (1) stay calm and limit the time you spend worrying about the pandemic, (2) stay prepared for working outside the laboratory, and (3) stay focused but separated from other family members during your home office hours to keep your research going. ${ }^{18}$

The impact of COVID-19 on the younger generation of researchers is of major relevance to their professional career in the world of science and therefore in the focus of several reports ${ }^{3,14,17}$ or comments, ${ }^{17-20}$ including an optimistic guide for the future. ${ }^{6}$ Details are discussed elsewhere. ${ }^{16,17}$

\section{Virtual Meetings: Challenges, Chances, and Perspectives}

Scientific communication, collaboration, networking, and training are essential elements of research, specifically in life sciences. Therefore, social distancing (and quarantine all 
the more) constitutes a major obstacle to permit successful research operations in a "business as usual" attitude. In particular, reduction in the ad hoc exchange of ideas that otherwise occurs through informal (and frequently spontaneous) face-to-face conversations at the bench has blocked a valuable information sharing channel. In the prepandemic era, this channel has been an essential and natural part of the training and discussing environment offered by established laboratories.

Moreover, cancelation of local seminars, workshops, grand rounds, annual national meetings, and international conferences has caused profound changes in "classic" scientific communication and in-person interactions. Consequently, these traditional events are currently lost both for established and early-stage scientists at all stages. Especially for the latter group, meeting and networking with colleagues are crucial opportunities for future collaborations, exchange of research visions, and career planning.

In times of COVID-19, video conferencing systems (e.g., Zoom, Teams, or GoToMeeting) or other teleconferencing platforms have become a standard of up-to-date communication among scientists. The fact that nearly all communication nowadays is electronic promotes other digital activities such as laboratory meetings, journal clubs, scientific seminars, and online training courses. Indeed, conferencing tools are heavily used by more than $90 \%$ of life scientists and represent an effective platform of communication and mentoring. ${ }^{3,6,18}$ Moreover, since the beginning of the pandemic, a steadily increasing proportion of scientists is attending virtual conferences of national and international societies. Thus, e-congresses are becoming a relevant format of scientific meetings. In fact, virtual workshops, seminars, and conferences may reach a larger audience because conference fees are reduced and neither traveling nor accommodation is required.

However, it remains to be seen what the long-term consequences of digital instead of face-to-face communication will be. The effects of online activities (including elearning) may have particular relevance for the quality and intensity of training and mentoring of young scientists. Therefore, in times of COVID-19, supervisors and academic teachers have a particular responsibility to prepare young scientists today for leadership positions in the world of science of tomorrow. ${ }^{21}$

\section{Current Edition}

When Professor Lorenzo Alberio was elected to organize and host the congress 2021 of the Society of Thrombosis and Hemostasis Research (GTH) in Lausanne, he could not anticipate the great burden that he was taking upon during the pandemic. "Across Borders", the motto of the 65th GTH Congress, is the mission and spirit of the GTH. The catchy slogan emphasizes the interdisciplinary character of hemostasis and thrombosis in research and clinical practice but also reflects multiple facets, including host country-specific language borders as well as intellectual, conceptual and, last but not least, organizational aspects of this year's congress. ${ }^{22}$
As announced, the scheduled Lausanne meeting will be an econference-a new experience to the congress president and his team but also to the GTH and its members.

Despite his enormous challenge, Lorenzo faithfully adhered to our invitation to be the guest editor again, this time for the Journal's traditional congress issue. Once more, he did a perfect job in organizing and coordinating this edition, including the peer review process of all contributions submitted by invited speakers. Due to his international reputation and energy, most of the plenary lecturers and keynote or state-of-the art session speakers accepted Lorenzo's invitation to present online and to write a concise review article. In fact, e-presentations during the conference plus corresponding publications in print will be perfectly fitting complementary elements to the congress attendees. We are therefore grateful to the speakers and authors for the dual task and the additional time required for writing and, whenever required, for revising a manuscript.

Overall, Lorenzo has been so successful in his invitation activities that the number of submissions exceeds the number of articles that can be printed in a single edition. Therefore, this issue represents part I of the GTH 2021 congress; part II of the conference will be published in an upcoming edition of the Journal. An introduction to the selection of topics and the invited articles of the annual GTH meeting is given in Professor Alberio's editorial. ${ }^{23}$

I am grateful to the authors and reviewers, the editorial board members, and editorial staff at Thieme. With this editorial, I also wish to express my thanks to our readers for their interest, loyalty, and suggestions. Stay safe in 2021 and remain optimistic that professional (and personal) life will return to normal once the pandemic is under control.

\section{Conflict of Interest}

The author declares that he has no conflict of interest.

\section{References}

1 Statista. Accessed December 23, 2020 at: https://de.statista.com/infografik/21489/globale-anzahl-der-taeglich-neu-gemeldeten-klinischen-studien-zum-coronavirus/2020

2 Scharf RE. Productivity of young experts in hemostasis and thrombosis before and during the SARS-CoV-2 pandemic - a special issue. Hamostaseologie 2020;40(03):255-256

3 Korbel JO, Stegle O. Effects of the COVID-19 pandemic on life scientists. Genome Biol 2020;21(01):113

4 National Library of Medicine. PubMed. Accessed December 23, 2020 at: www.nlm.nih.gov2020

5 Eisen MB, Akhmanova A, Behrens TE, Weigel D. Publishing in the time of COVID-19. eLife 2020;9:e57162

6 Termini CM, Traver D. Impact of COVID-19 on early career scientists: an optimistic guide for the future. BMC Biol 2020;18 (01):95

7 Eisen MB, Akhmanova A, Behrens TE, Harper DM, Weigel D, Zaidi $\mathrm{M}$. Implementing a "publish, then review" model of publishing. eLife 2020;9:e64910

8 Ramanan M, Stolz A, Rooplalsingh R, Billot L, Myburgh J, Venkatesh B. An evaluation of the quality and impact of the global research response to the COVID-19 pandemic. Med J Aust 2020; 213(08):380-380.e1 
9 Mehra MR, Desai SS, Kuy S, Henry TD, Patel AN. Cardiovascular disease, drug therapy, and mortality in Covid-19. N Engl J Med 2020;382(25):e102

10 Mehra MR, Desai SS, Ruschitzka F, Patel AN. RETRACTED: Hydroxychloroquine or chloroquine with or without a macrolide for treatment of COVID-19: a multinational registry analysis. Lancet 2020;S0140-6736(20)31180-6. doi: 10.1016/S0140-6736(20) 31180-6

11 Mehra MR, Desai SS, Kuy S, Henry TD, Patel AN. Retraction: cardiovascular disease, drug therapy, and mortality in Covid-19. N Engl J Med. DOI: 10.1056/NEJMoa2007621. N Engl J Med 2020; 382(26):2582

12 Mehra MR, Ruschitzka F, Patel AN. Retraction-Hydroxychloroquine or chloroquine with or without a macrolide for treatment of COVID-19: a multinational registry analysis. Lancet 2020;395 (10240): 1820

13 The Editors of The Lancet Group. Learning from a retraction. Lancet 2020;396(10257):1056

14 Myers KR, Tham WY, Yin Y, et al. Unequal effects of the COVID-19 pandemic on scientists. Nat Hum Behav 2020;4(09):880-883

15 Rijs C, Fenter F. The academic response to COVID-19. Front Public Health 2020;8:621563

16 Scharf RE. Implications and impact of the COVID-19 pandemic on life scientists. 2020 (article is submitted and under review)
17 Scharf RE. Enormer Anstieg der Produktivität. Auswirkungen der COVID-19-Pandemie auf den Alltag von Lebenswissenschaftlern. Forschung \& Lehre, DHV 2021;28(02):132-133

18 Subramanya SH, Lama B, Acharya KP. Impact of COVID-19 pandemic on the scientific community. Qatar Med J 2020;2020(01): 21

19 Su L. My lab is closed to me because of the coronavirus. Here's how I'm planning to stay productive. Nature 2020 (e-pub ahead of print). Doi: 10.1038/d41586-020-00986-6

20 Campos MM. The impact of COVID-19 on women in science reflections on the WISCovid19 conference. 2020. Accessed December 23, 2020 at: https://ellipse.prbb.org/the-impact-ofcovid-19-on-women-in-science-reflections-on-the-wiscovid19conference/

21 Alba Network. The impact of COVID-19 on women and minorities in science. 2020, Accessed December 23, 2020 at: http://www. alba.network/impact-covid-19-women-and-minorities-science

22 Scharf RE. About mentees and mentors: what kind of advanced training should young scientists receive? - A personal reflection. Hamostaseologie 2020;40(03):379-381

23 Alberio L. GTH 2021: simply online ... worth experiencing. Hamostaseologie 2020;40:558-559

24 Alberio L. GTH 2021: ACROSS BORDERS. Hamostaseologie 2021; 41:5-6 